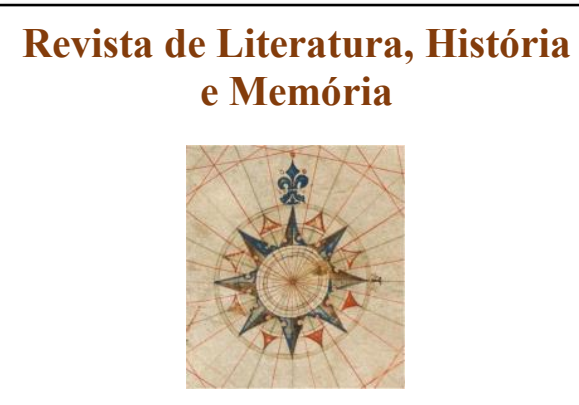

Seção: Pesquisa em Letras no contexto Latino-americano e Literatura, Ensino e Cultura

ISSN 1983-1498

VOL. 16 - No 28 - 2020

U N I O E S T E / CA S C A V E L - p. 225-241

\title{
ESPAÇOS HETEROTÓPICOS, ROSTOS-PAISAGENS \\ E ESPÉCIES COMPANHEIRAS: UM ESTUDO ECOCRÍTICO DA OBRA ROMANESCA DE GRACILIANO RAMOS
}

\section{Heterotopic spaces, faces-landscapes and companion species: an ecocritical study of the novelistic work by Graciliano Ramos}

\section{Cosme Rogério Ferreira ${ }^{1}$}

RESUMO: Este artigo consiste em apresentar uma leitura da obra romanesca do escritor Graciliano Ramos (1892-1953) numa perspectiva ecocrítica, ramo dos estudos literários que objetiva as interfaces entre a literatura e o meio ambiente. O trabalho articula as noções de espaço, heterotopia, rostidade e espécies companheiras para demonstrar relações entre ser humano e ambiente na produção do consagrado romancista alagoano. Para tanto, lançamos mão da técnica de pesquisa bibliográfica, reunindo autores que auxiliam no processo de reflexão sobre os temas em jogo em tais obras, como Alaimo (2008), Bourdieu (1996; 2003), Brandão (2017), Deleuze e Guattari (2012), Gaard (2010), Glotfelty (1996), Foucault (2009) e Haraway (2017). Como resultado, verifica-se que a obra de Graciliano Ramos, além de ser um importante documento da realidade social brasileira, é também uma obra ecocrítica, no sentido de que se abre às reflexões sobre os lugares/espaços onde foram produzidas e onde se desenvolvem as narrativas.

PALAVRAS-CHAVE: Graciliano Ramos; Heterotopias; Rostidade; Espécies companheiras.

ABSTRACT: This article consists of presenting a reading of the novelistic work of the writer Graciliano Ramos (1892-1953) in an ecocritical perspective, a branch of literary studies that aims at the interfaces between literature and the environment. The work articulates the notions of space, heterotopy, rostity and companion species to demonstrate the relationships between human beings and the environment in the production of the renowned Alagoan novelist. To th-is end, we used the technique of bibliographic research, bringing together authors who assist in the process of reflection on the themes at stake in such works, such as Alaimo (2008), Bourdieu (1996; 2003), Brandão (2017), Deleuze and Guattari (2012), Gaard (2010), Glotfelty (1996), Foucault (2009) and Haraway (2017). As a result, it turns out that the work of Graciliano Ramos, in addition to being an important document of the Brazilian social reality, is also an ecocritical work, in the sense that it is open to reflections on the places / spaces where they were produced and where they are developed the narratives.

KEYWORDS: Graciliano Ramos; Heterotopy; Rostity; Companion species.

\section{INTRODUÇÃO}

Desde que veio a lume, há quase noventa anos, a obra de Graciliano Ramos é estudada a partir de muitas e diferentes perspectivas. A literatura tem sido aberta às investigações das

1 Doutorando em Linguística e Literatura pela Universidade Federal de Alagoas (Ufal). Professor do Ensino Básico, Técnico e Tecnológico do Instituto Federal de Alagoas (Ifal/Campus Batalha). Contato: cosme.ferreira@ifal.edu.br. 
mais variadas correntes teóricas, sendo que a razão mais ampla dessa abertura reside no fato da interligação entre o universo literário e outros universos de significação. Nossa proposta consiste, particularmente, em apresentar um estudo da obra romanesca graciliânica numa perspectiva ecocrítica, ramo dos estudos literários que objetiva as interfaces entre a literatura e o meio ambiente.

Pretendemos articular especificamente os conceitos de espaço, heterotopia, rostidade e espécies companheiras para demonstrar as relações entre ser humano e ambiente na construção biobibliográfica do consagrado romancista alagoano. Para tanto, lançamos mão da técnica de pesquisa bibliográfica, reunindo autores que auxiliam no processo de reflexão sobre os temas em jogo nos enredos romanescos graciliânicos.

Na primeira parte, percorreremos um escorço da trajetória de Graciliano, destacando a formação de seu habitus literário, da infância até a gestão da prefeitura de Palmeira dos Índios, quando foi descoberto como escritor/romancista. Em seguida, utilizando as categorias foucaultianas de lugares utópicos e heterotópicos, identificaremos os lugares da memória graciliânica que lhe foram cruciais nesse processo. Por fim, abordando os quatro romances de Graciliano como uma unidade estética, apresentaremos uma síntese de como a naturezacultura, para usar uma expressão de Donna Haraway (2017), foi representada nessas obras.

\section{GRACILIANO RAMOS: A GÊNESE SOCIAL DO HABITUS DO ESCRITOR}

Em termos sociológicos, esta é a condição para que toda leitura se converta também em uma interpretação: saber como o autor habita o mundo e quais são as forças sociais que o habitam. Ao visar a leitura ecocrítica de uma obra romanesca com o fim de observar como o seu autor recriou fíccionalmente o cosmo físico-social em que estava inserido, convém que conheçamos também o seu próprio lugar, o espaço onde produziu sua obra, o chão a partir de onde ele observou a realidade. Para tal análise, tomamos das perspectivas sociológicas bourdieusianas e eliasianas as chaves conceituais que nos permitem combinar aqui distintos métodos. De Bourdieu emprestamos o conceito de campo, compreendido como um espaço de relações de forças - portanto um espaço de relações de poder - onde acontecem as lutas entre os detentores de diferentes tipos de capital (econômico e cultural) pelo seu domínio. Dependendo da posição (dominantes/dominados) que ocupam na estrutura do campo de poder, isto é, de como estão distribuídos os distintos capitais, os agentes tomam suas posições pela conservação ou pela subversão do campo - esta sempre em oposição à conservação, 
embora não implique necessariamente alterações nos princípios estruturantes do campo. Nas palavras de Bourdieu (1996, p. 64):

eu diria que cada autor, enquanto ocupa uma posição no espaço, isto é, em um campo de forças [...] só existe e subsiste sob as limitações estruturadas do campo; mas ele também afirma a distância diferencial constitutiva de sua posição, seu ponto de vista, entendido como vista a partir de um ponto..

Em síntese, a teoria social de Bourdieu diz que os campos são espaços de posições, que se traduzem em espaços de tomadas-de-posição (escolhas) mediados pelo espaço de disposições ou de gostos (habitus). Esta chave analítica se aproxima com a de Elias, no qual o habitus é a composição social do indivíduo, construída processualmente na relação dinâmica entre o indivíduo e a sociedade. O método de Elias para o estudo dessa relação consiste em tomar o indivíduo como um processo psicossocial, uma trajetória onde incidem e se cruzam processos de psicogênese e sociogênese, que buscam capturar a estrutura social de personalidade do indivíduo (ELIAS, 1995).

Analisando o processo-Graciliano, averiguamos que o autor nasceu inserido nos padrões da velha sociedade brasileira, marcada pelas relações patriarcais e coronelísticas, com forte influência da família, da igreja católica, da polícia local e das oligarquias na vida política provinciano-estadual. Como o sociólogo e crítico literário Antonio Candido descreveu, Graciliano não somente foi testemunha dessas lentas mudanças sociais, mas, principalmente, foi partícipe de sua organização, na condição de jornalista, administrador e político. Essa experiência animaria a sua atitude radical posteriormente assumida como "receita que lhe pareceu viável para trazer o progresso, com o fim do caciquismo e atenuação da rígida diferença de classes, num país apenas saído do regime de castas da escravidão" (CANDIDO, 1996, p. 11). Seu pai, o coronel Sebastião Ramos, negociante de miudezas, era filho de um antigo senhor de engenho arruinado pelo processo de substituição dos engenhos pelas usinas, no fim do Segundo Império. Sua mãe, Maria Amélia Ferro Ramos (Mariquinha), era filha de pecuaristas. Sob rígida educação, que incluía castigos físicos, como a palmatória, a muito custo o menino triste aprendeu a ler e a desenvolver o gosto pela leitura, graças, sobretudo, à atenção afetuosa de uma prima chamada Emília e, quando adolescente, ao incentivo à escrita jornalística dado pelo intelectual Mário Venâncio, seu professor de geografia em Viçosa.

Como dissemos em um livro anterior (cf. FERREIRA, 2015), Graciliano passou pouco tempo na escola e não se tornou bacharel, não se enquadrando no perfil comum do intelectual de sua época, exemplar da "praga do Bacharelismo" - expressão que Sérgio Buarque de Holanda utiliza em Raízes do Brasil para referir-se à tendência nossa de exaltar a 
personalidade individual acima de tudo, com dignidade e importância conferidas pelo título de “doutor". Todavia, a autodidaxia de Graciliano não ocorreu fora das oportunidades que jovens como ele dispunham, por sua própria condição social. De acordo com Sérgio Miceli (2012, p. 118):

Tratava-se de um autodidatismo peculiar para rapazes de tal condição social, ora próximo de um aquecimento doméstico, ora costeando a absorção de habilidades pouco usuais. Essa educação caprichada, incutida por adultos cultos e requintados, nada tinha a ver com o esforço solitário e nada gratificante de moços destituídos de haveres.

Entre os afazeres comerciais junto ao pai, o jovem sertanejo esmerava-se na literatura, a sua "provisão de sonhos". Contudo, as condições por ele vividas mais o constrangeram do que o estimularam à atividade literária. $\mathrm{Na}$ contramão, foi por meio dela que Graciliano encontrou refúgio para suas crises existenciais, aprofundadas 1) pela frustração com o abandono da carreira jornalística iniciada em 1914 no Rio de Janeiro - centro gravitacional da atividade literária nacional brasileira -, por causa da tragédia familiar onde morreram três irmãos e um sobrinho seus, vítimas de um surto de peste bubônica que dizimou a cidade em 1915 ; 2) pela responsabilidade de cuidar de quatro filhos pequenos após a morte, em 1920, de sua primeira esposa, com quem ele enfrentou a própria família para levar adiante o namoro, uma vez que seus pais não viam o relacionamento com bons olhos; e 3) pelas limitações características do modo de vida provinciano da antiga cidade, movida a fuxicos e intrigas políticas.

Em 1924, numa profunda crise depressiva, Graciliano pensou em dar cabo de sua própria vida. À filha Clara Ramos ele confessou sobre a situação experimentada: "encontrei dificuldade séria, pus-me a ver inimigos em toda a parte e desejei suicidar-me. Realmente julgo que me suicidei” (G. RAMOS apud C. RAMOS, 1979, p. 54). Foi nesse tempo que surgiram alguns contos que, desenvolvidos ao longo dos anos seguintes, originaram os romances Caetés (1933), S. Bernardo (1934) e Angústia (1936). Sua descoberta como romancista, através dos relatórios que redigiu ao governador Álvaro Paes prestando contas de sua administração como prefeito repercutiram na imprensa carioca-nacional, se tornando um dos mais comentados casos do reconhecimento de um verdadeiro artista das letras na história do campo literário brasileiro. 


\section{ESPAÇOS HETEROTÓPICOS NA TRAJETÓRIA GRACILIÂNICA}

Um dos pensadores que contribuíram conceitualmente para as elaborações teóricas da ecocrítica, conforme ressalta Gloftelty na introdução de Ecocriticism reader - landmarks in Literary ecology (1996), foi o francês Michel Foucault, sobretudo por conta de suas reflexões acerca da noção de espaço, que tiveram impacto na ecologia humana, ramo que estuda as relações entre o ser humano e o seu ambiente. Em Outros espaços, conferência de 1967, publicada pela primeira vez em 1984, Foucault apresentou a história como a "grande mania" que obcecou o século XIX, ao passo que o século XX constituiu-se na época da geografia, do espaço, do simultâneo, da justaposição, das relações de vizinhança e distanciamento. Trata-se de um mundo que se experimenta mais como uma rede que religa pontos e entrecruza sua trama do que uma grande via que se desenvolveria através dos tempos. Segundo o filósofo, "certos conflitos ideológicos que animam as polêmicas de hoje se desencadeiam entre os piedosos descendentes do tempo e os habitantes encarniçados do espaço" (FOUCAULT, 2009, p. 411). No entanto, mesmo que o século XX tenha significado a primazia da geografia, substituindo a primazia da história no século anterior, essa ruptura entre tempo e espaço não pode se dar em absoluto pelo simples motivo de que a noção de espaço é de natureza histórica: "o próprio espaço na experiência ocidental tem uma história” (FOUCAULT, 2009, p. 411).

Adotando a perspectiva do estruturalismo, abordagem definida pelo filósofo como um "esforço para estabelecer, entre elementos que podem ter sido dispersos através do tempo, um conjunto de relações que os faz aparecer justapostos, opostos, comprometidos um com o outro, em suma, que os faz aparecer como uma espécie de configuração" (FOUCAULT, 2009, p. 411), Foucault afirma que não se trata de negar o tempo, mas de "uma certa maneira de tratar o que se chama tempo e o que se chama de história" (FOUCAULT, 2009, p. 411). Em sua breve história do espaço, Foucault começa pela Idade Média, onde o espaço é entendido como um conjunto hierarquizado de lugares: sagrados e profanos, protegidos e indefesos, urbanos e rurais (vida real). Na cosmologia medieval havia lugares supracelestes, que faziam oposição ao lugar celeste, que, por sua vez, se opunha ao lugar terrestre. Toda essa hierarquia, oposição e entrecruzamento de lugares era o que poderia ser chamado, grosso modo, de espaço de localização. A partir de Galileu Galilei, no século XVII, a extensão tomou o lugar da localização, substituída, atualmente, pelo posicionamento, definido pelas relações de vizinhança entre os pontos ou elementos. Essa noção de posicionamento é próxima da noção de posição em Bourdieu, para o qual posicionar-se é ocupar um ponto no espaço, por sua vez 
definido pelo acúmulo mais ou menos de dois tipos de capital: o econômico e o cultural. $\mathrm{Na}$ teoria bourdieusiana, o espaço de posições se retraduz num espaço de tomadas-de-posição (escolhas), mediado pelo espaço de disposições (habitus) (BOURDIEU, 2003).

Voltando a Foucault, de modo concreto, o problema do lugar ou dos posicionamentos se propõe em termos demográficos: não se trata somente da questão de saber se haverá espaço suficiente para os seres humanos no mundo, mas também de saber que relações de vizinhança, de estocagem, circulação, localização, de classificação dos elementos humanos devem ser mantidos de preferência em tal ou tal situação para se chegar a tal ou tal fim. Nossa época seria aquela em que o espaço se oferece a nós sob a forma de relações de posicionamentos.

$\mathrm{Na}$ contemporaneidade, o espaço não foi ainda dessacralizado como foi o tempo no século XIX: a vida é comandada por um certo número de oposições que a instituição e a prática ainda não ousaram atacar. Citando Bachelard e os fenomenólogos, Foucault diz que esses pensadores nos ensinaram que o espaço não é um espaço homogêneo, mas carregado de qualidades e, talvez, seja até povoado de fantasmas. Foucault reconhece que essas análises são fundamentais para a reflexão contemporânea, mas elas se referem sobretudo ao espaço de dentro, sendo que ele pretendia falar sobre o espaço de fora:

O espaço no qual vivemos, pelo qual somos atraídos para fora de nós mesmos, no qual decorre precisamente a erosão de nossa vida, de nosso tempo, de nossa história, esse espaço que nos corrói e nos sulca é também em si mesmo um espaço heterogêneo. Dito de outra forma, não vivemos em uma espécie de vazio, no interior do qual poderiam situar os indivíduos e as coisas. Não vivemos no interior de um vazio que se encheria de cores com diferentes reflexos, vivemos no interior de um conjunto de relações que definem posicionamentos irredutíveis uns aos outros e absolutamente impossíveis de ser sobrepostos (FOUCAULT, 2009, p. 414).

Assim, os espaços que estão ligados a todos os outros, contradizendo contudo todos os outros posicionamentos, são de dois grandes tipos:

a) as utopias: posicionamentos sem lugar real. “(...) É a própria sociedade aperfeiçoada ou é o inverso da sociedade mas, de qualquer forma, essas utopias são espaços que fundamentalmente são essencialmente irreais" (FOUCAULT, 2009, p. 414-415);

b) as heterotopias: opostas às utopias, referem-se a lugares reais, porém não hegemônicos da sociedade, isto é, que compõem o entorno social (prisão, escola, hospital, biblioteca, museu, jardim, cemitério etc.). 
Tomando o segundo grande tipo como objeto de análise, Foucault descreve as heterotopias a partir de suas características. Ele começa pelas relações mistas entre utopia e heterotopia, como num espelho, que é uma utopia, porque é um lugar sem lugar, e é simultânea e igualmente uma heterotopia, na medida em que o espelho existe na realidade e que tem um efeito retroativo no lugar ocupado.

Considerando que não há nenhuma cultura do mundo que não se constitua de heterotopias, o filósofo as divide, por sua vez, em dois outros grandes tipos: as heterotopias de crise, típicas das sociedades ditas "primitivas", que são "lugares privilegiados, ou sagrados, ou proibidos, reservados aos indivíduos que se encontram, em relação à sociedade ou ao meio humano no interior do qual eles vivem, em estado de crise" (FOUCAULT, 2009, p. 416), como na adolescência, na menstruação, no resguardo etc.; e as heterotopias do desvio, que cada vez mais substituem as heterotopias de crise, e são aqueles lugares em que há indivíduos cujo comportamento desvia da média ou da norma exigida, como as prisões, os hospícios, os asilos etc. Na trajetória de Graciliano Ramos, que esteve preso em duas ocasiões, a heterotopia do desvio marcante é a prisão de Ilha Grande, para onde o escritor foi levado apulso em 1936, sem acusação formal, sem processo, sem julgamento. Ao mesmo tempo, Ilha Grande foi também para Graciliano, que nunca fez curso superior, uma espécie de "universidade", uma heterotopia do tempo, pois os intelectuais que lá estavam confinados passavam o tempo proferindo palestras, ministrando seminários e conferências entre eles e outros presos.

Como se observa, cada heterotopia tem funcionamento preciso e determinado no interior da sociedade, mas a mesma heterotopia pode, segundo a sincronia da cultura na qual se encontra, ter um funcionamento ou outro, como, por exemplo, a curiosa heterotopia do cemitério, sobre a qual transcrevemos por completo esta heterotopologia foucaultiana:

O cemitério é certamente um lugar diferente em relação aos espaços culturais habituais, é um espaço que está, no entanto, em ligação com o conjunto de todas os posicionamentos da cidade ou da sociedade ou do campo, já que cada indivíduo, cada família tem parentes no cemitério. $\mathrm{Na}$ cultura ocidental, o cemitério praticamente sempre existiu. Mas sofreu mutações importantes. Até o fim do século XVIII, o cemitério estava situado no próprio centro da cidade, ao lado da igreja. Ali existia toda uma hierarquia de sepulturas possíveis. Havia o ossuário no qual os cadáveres perdiam até o último traço de individualidade, havia alguns túmulos individuais, e depois havia sepulturas dentro das igrejas. Essas sepulturas eram de duas espécies. Ora simplesmente lajes com uma inscrição, ora mausoléus com estátuas. Esse cemitério, que se localizava no espaço sagrado da igreja, adquiriu nas civilizações modernas um aspecto totalmente diferente e, curiosamente, foi na época em que a civilização se tornou, como 
se diz muito grosseiramente, "atéia" que a cultura ocidental inaugurou o que se chama culto dos mortos. (...) Em todo caso, foi a partir do século XIX que cada um teve direito à sua pequena caixa para sua pequena decomposição pessoal; mas, por outro lado, foi somente a partir do século XIX que se começou a colocar os cemitérios no limite exterior das cidades. Correlativamente a essa individualização da morte e à apropriação burguesa do cemitério nasceu uma obsessão da morte como "doença". São os mortos, supõe-se. que trazem as doenças aos vivos, e é a presença e a proximidade dos mortos ao lado das casas, ao lado da igreja, quase no meio da rua, é essa proximidade que propaga a própria morte. Esse grande tema da doença disseminada pelo contágio dos cemitérios persistiu no fim do século XVIII: e foi simplesmente ao longo do século XIX que se começou a processar a remoção dos cemitérios para a periferia. Os cemitérios constituem, então, não mais o evento sagrado e imortal da cidade, mas a "outra cidade", onde cada família possui sua morada sombria (FOUCAULT, 2009, p. 417-418).

O cemitério de Palmeira dos Índios, por sua própria natureza heterotópica, é um lugar que cumpre um papel de múltiplos significados na trajetória de Graciliano: um lugar cujas paredes brancas compuseram as suas saudosas lembranças, conforme relatado numa carta, de quando de sua primeira experiência no Rio (cf. RAMOS, 2011, p. 45); por ter tido problemas de superlotação quando do surto de peste bubônica que dizimou a população em 1915 e abateu a família do então cronista de jornal; e por ter sido um espaço público sob sua administração, quando prefeito da cidade, entre 1928 e 1930. É a "outra cidade", no dizer de Foucault, onde habitam os “munícipes que não reclamam”, no dizer do prefeito Graciliano.

Retornando aos atributos das heterotopias, vale dizer que elas têm o poder de justapor em um só lugar real vários espaços, posicionamentos diversos que são em si próprios incompatíveis, como, por exemplo, o teatro, o cinema e o jardim - espécie de heterotopia feliz e universalizante. Elas estão ligadas, mais frequentemente, a recortes de tempo, dando para o que pode se chamar de heterocronias. Em uma sociedade como a nossa, heterotopia e heterocronia se organizam e se arranjam de maneira muito complexa. Há as heterotopias do tempo, que se acumula infinitamente, como museus e bibliotecas. Como exemplos, destaco três heterocronias que são cruciais na formação intelectual de Graciliano, além da prisãouniversidade na qual viveu por cerca de dez meses: 1) a biblioteca de Mário Venâncio, funcionário dos Correios e seu professor de geografia em Viçosa, que lhe fornecia a sua "provisão de sonhos", quando adolescente; 2) o balcão da Loja Sincera, casa comercial de seu pai, o coronel Sebastião Ramos, em Palmeira dos Índios, onde passou a morar a partir de 1910, aos 18 anos. Ali, o jovem comerciante e aspirante a escritor esmerava-se na leitura de clássicos diversos da literatura universal; e 3) a Livraria José Olympio, ponto gravitacional da intelligentsia brasileira entre as décadas de 1930 e 1950, onde o já consagrado escritor 
Graciliano comparecia todas as tardes, reunido com outros agentes do campo literário (escritores, editores, leitores, críticos literários).

Há as heterotopias que são ligadas ao tempo no que ele tem de mais fútil, como as festas e as feiras. Foi numa heterotopia dessas que, em 1927, Graciliano conheceu aquela que seria a sua segunda esposa: Heloísa Medeiros. No caso, a Festa de Nossa Senhora do Amparo, padroeira de Palmeira dos Índios, que acontece no período dos festejos de Natal e Ano Bom, citada no romance Caetés, nas Cartas e em Viventes das Alagoas. E há as heterotopias crônicas, como as casas de veraneio. A de maior importância na infância e na juventude de Graciliano foi a fazenda da família em Buíque, no sertão pernambucano, onde o menino Graciliano se entendeu como gente e onde passava temporadas de férias. As experiências vividas nessa fase, desde as primeiras e enevoadas lembranças, até por volta de seus 12 anos de idade, foram narradas na obra memorialística Infância (1945). Foi naquela paisagem que Graciliano vivenciou a experiência caatingueira e sobre a qual escreveu, ainda que sem mencionar um local específico do enredo, em Vidas secas.

Por fim, eis um último traço das heterotopias: elas têm, em relação ao espaço restante, a função de criar um espaço de ilusão que denuncia como mais ilusório ainda qualquer espaço real, todos os posicionamentos no interior dos quais a vida humana é compartimentalizada. Foucault encerra as suas reflexões citando os bordeis e colônias como dois tipos extremos de heterotopia, e elege o barco, "um pedaço de espaço flutuante, um lugar sem lugar, que vive por si mesmo, que é fechado em si mesmo e lançado ao infinito do mar" (FOUCAULT, 2009, p. 421), como a heterotopia por excelência: "ao mesmo tempo não apenas, certamente, o maior instrumento de desenvolvimento econômico (...), mas a maior reserva da imaginação" (FOUCAULT, 2009, p. 422). Por três vezes o navio - esta "heterotopia por excelência", por carregar consigo o sonho, o devaneio, a aventura, ao mesmo tempo em que é um chão, portanto um lugar de fixação, de enraizamento - marcou a trajetória graciliânica: 1) primeiramente em 1914, quando foi aventurar-se pela primeira vez no Rio de Janeiro, visando seguir a carreira literário-jornalística; 2) ao retornar às Alagoas no ano seguinte, diante da tragédia da peste que abateu a sua casa; 3) em sua volta ao Rio em 1936, na condição de preso político do governo Vargas, experiência que foi imortalizada em Memórias do cárcere. Ele nunca mais voltaria às Alagoas. 


\section{A OBRA ROMANESCA GRACILIÂNICA NUMA PERSPECTIVA ECOCRÍTICA: ROSTOS-PAISAGENS E ESPÉCIES COMPANHEIRAS}

Dentre heterotopias do tempo que Graciliano produziu, isto é, seus livros e, em especial, seus romances, nota-se que os três primeiros (Caetés, São Bernardo e Angústia) trazem a marca da utopia: os protagonistas narram os seus desejos e devaneios, embora não realizáveis. Vidas secas é a própria realização dos devaneios dos romances de outrora. Senão vejamos.

Em Caetés, romance escrito entre 1925 e 1930, mas somente publicado em 1933, João Valério é um comerciário aspirante a escritor que deseja, através disso, angariar poder simbólico na provinciana Palmeira dos Índios, uma vez que não é proprietário e nem bacharel, condições que lhe garantiriam boa colocação ou status em seu meio social. Para tanto, ele investe na composição de um romance histórico inacabável sobre os índios caetés, cujas personagens seriam inspiradas em conhecidos seus na cidade. A sua insatisfação surge diante da não-realização do sonho de ser "selvagem" como aqueles índios, isto é, de consumar seu amor proibido com Luísa, a mulher do patrão:

De repente imaginei o morubixaba pregando dois beijos na filha do pajé. Mas, refletindo, compreendi que era tolice. Um selvagem, no meu caso, não teria beijado Luísa: tê-la-ia provavelmente jogado para cima do piano, com dentadas e coices se ela se fizesse arisca. Infelizmente não sou selvagem. E ali estava, mudando a roupa com desânimo, civilizado, triste, de cuecas (RAMOS, 2019, p 25).

A paisagem da cidade de Palmeira dos Índios, cuja vista é dada por João Valério ao leitor a partir da calçada da Matriz de Nossa Senhora do Amparo, é encarada pelo protagonista mais do que como uma metáfora de sua vida. João Valério parece reconhecer que Palmeira dos Índios e ele têm algo de consubstancial:

Montes à esquerda, próximos, verdes; montes à direita, longe, azuis; montes ao fundo, muito longe, brancos, quase invisíveis, para as bandas do $\mathrm{S}$. Francisco. Acendi um cigarro. E imaginei com desalento que havia em mim alguma coisa daquela paisagem: uma extensa planície que montanhas circulam. Voam-me desejos por toda a parte, e caem, voam outros, tornam a cair, sem força para transpor não sei que barreiras. Ânsias que me devoram facilmente se exaurem em caminhadas curtas por esta campina rasa que é a minha vida (RAMOS, 2019, p. 164).

Tal consubstanciação nos remete às reflexões ecosóficas de Deleuze e Guattari (2012), quando tratam da noção de rostidade, marcada pelo cruzamento de dois eixos de interpretação 
semiótica: o eixo da significância e o da subjetivação. A significância demanda um "muro branco" no qual são escritos seus signos e redundâncias. A subjetivação existe como um "buraco negro" onde são alojadas as consciências e suas redundâncias. Um rosto, nessa perspectiva, é um sistema muro branco-buraco negro: "Um rosto não é animal, mas tampouco é humano em geral, há mesmo algo de absolutamente inumano no rosto" (DELEUZE e GUATTARI, 2012, p. 40). Mais adiante, demonstrando a relação sistêmica entre rosto e paisagem, como ocorre no caso de João Valério-Palmeira dos Índios no excerto graciliânico acima transcrito,

não há rosto que não envolva uma paisagem desconhecida, inexplorada, não há paisagem que não se povoe de um rosto amado ou sonhado, que não desenvolva um rosto por vir ou já passado. Que rosto não evocou as paisagens que amalgamava, o mar e a montanha, que paisagem não evocou o rosto que a teria completado, que lhe teria fornecido o complemento inesperado de suas linhas e de seus traços (DELEUZE e GUATTARI, 2012, p. 43).

Essa noção de rostidade guarda similitude com o conceito de trans-corporalidade, oriundo da ecocrítica feminista, proposto por Alaimo (2008) e entendido por Brandão "como uma defesa da integração humano-ambiente, na qual humano e não humano estão imbricados um no outro" (BRANDÃO, 2017, p. 964). A noção de trans-corporalidade, com todas as interconexões que abrange, remete à interseccionlidade proposta por Gaard (2010) para abordar "um território que é, ao mesmo tempo, material e discursivo; que é natural e cultural, mas também biológico e textual” (BRANDÃO, 2017, p. 964).

Em S. Bernardo, romance publicado em 1934, o ambiente da ação é a área rural de Viçosa, na Zona da Mata alagoana. O protagonista Paulo Honório, embora homem de negócios inclinado ao pragmatismo próprio de um fazendeiro, arriscando-se na atividade de escritor. Na elaboração textual de suas memórias, há o expresso desejo de uma vida simples de roceiro, como se observa em seus devaneios sobre o povoado de seu Ribeiro:

Penso no povoado onde seu Ribeiro morou, há meio século. Seu Ribeiro acumulava, sem dúvida, mas não acumulava para ele. Tinha uma casa grande, sempre cheia, o jerimum caboclo apodrecia na roça - e por aquelas beiradas ninguém tinha fome. Imagino-me vivendo no tempo da monarquia, à sombra de seu Ribeiro. Não sei ler, não conheço iluminação elétrica nem telefone. Para me exprimir recorro a muita perífrase e muita gesticulação. Tenho, como todo mundo, uma candeia de azeite, que não serve para nada, porque à noite a gente dorme. Podem rebentar centenas de revoluções. Não receberei notícia delas. Provavelmente sou um sujeito feliz.

Com um estrecimento, largo essa felicidade que não é minha e encontro-me 
aqui em S. Bernardo, escrevendo (RAMOS, 2008, p. 219).

Note-se que há uma denúncia, nas entrelinhas: o modo de vida capitalista, que reduz o mundo a uma mercadoria, representado pela acumulação e pela escrituração, se afasta da relação com a natureza. Já o modo de vida do roceiro, pertencente à classe explorada e excluída, representa a utopia da integração com a natureza, onde a fartura é simbolizada pelo jerimum caboclo que apodrecia na roça, e por ninguém passar fome por aquelas beiradas.

O terceiro romance, Angústia, de 1936, retoma por locus o ambiente citadino. A cidade retratada é Maceió, que testemunhava os acontecimentos e mudanças daquela conturbada década. No romance temos o drama do jornalista Luís da Silva que, insatisfeito com a monotonia que vivia na capital alagoana - uma "vida de sururu", segundo ele -, deseja viver como viajante, divagando à beira-mar:

Se pudesse, abandonaria tudo e recomeçaria as minhas viagens. Esta vida monótona, agarrada à banca das nove horas ao meio-dia e das duas às cinco, é estúpida. Vida de sururu. Estúpida. Quando a repartição se fecha, arrastome até o relógio oficial, meto-me no primeiro bonde de Ponta-da-Terra (RAMOS, 2019b, p. 8).

A metáfora do sururu, molusco bivalve encontrável na lama dos manguezais e que serve de prato típico da culinária alagoana, é utilizada pelo protagonista tanto para descrever a vida que levava na cidade quanto à vida da própria cidade, que em nome da "modernidade" está, inclusive, menos arborizada (o narrador-personagem chega a dizer que outrora se podia ler o noticiário da polícia embaixo das árvores do passeio público) e, por conta disso, também mais quente:

À medida que o carro se afasta do centro sinto que me vou desanuviando. Tenho a sensação de que viajo para muito longe e não voltarei nunca. Do lado esquerdo são as casas da gente rica, dos homens que me amedrontam, das mulheres que usam peles de contos de réis. Diante delas, Marina é uma ratuína. Do lado direito, navios. Às vezes há diversos ancorados. Rolam bondes para a cidade, que está invisível, lá em cima, distante. Vida de sururu. (...)

O calor aqui também é grande demais. E faltam plantas. Apenas, um pouco afastados, coqueiros macambúzios, perfilados, como se esperassem ordens (RAMOS, 2019b, p. 9).

Em Vidas secas temos o melhor acabamento do sistema rosto-paisagem graciliânico. Publicado em 1938, no derradeiro romance de Graciliano, “onde a vida é a mais difícil de todas, por ser silenciosa e extremamente seca" (ALVES, 2011, p. 76) e o drama é "justamente 
êsse (sic) entrosamento da dor humana na tortura da paisagem", encontramos Fabiano, que "ainda não atingiu o estádio da civilização em que o homem se liberta mais ou menos dos elementos" (CANDIDO, 1961, p. 41).

No capítulo Mudança, o primeiro do livro, há uma ironia digna de comparação com um dos chistes que Rafael Sanzio colocou no afresco da Stanza della Segnatura, em Roma, popularmente conhecido como A escola de Atenas, no qual o artista representou Heráclito (o filósofo das mudanças, das impermanências) escrevendo com expressões melancólicas, apoiado em um banco de mármore, um fundamento sólido, ligado à ideia da firmeza e imutabilidade das coisas. Já a pintura literária de Graciliano se inicia apresentando os juazeiros que alargavam duas manchas verdes na planície avermelhada, e nos dá uma ilusão de ótica - a de que o movimento é, na verdade, das árvores: "Os juazeiros aproximaram-se, recuaram, sumiram-se" (RAMOS, 2018, p. 27). Mas o fato é que as que se aproximaram, recuaram e sumiram foram as pessoas em caminhada, em relação aos juazeiros, que estão plantados no mesmo lugar. A família de retirantes é quem passa por aquelas árvores. Mas, como essa caminhada, essa mudança, acontece na esteira da permanência, são os juazeiros que passam por ela. Isto é, ela caminha, mas parece parada no tempo.

Um último aspecto que merece destaque, especialmente no que se refere à ecologia do ser humano em Vidas secas, é a relação da família de retirantes com a cachorra Baleia. Por vezes, essa relação é estudada a partir da dicotomização homem/bicho, humano/animal. Há um trecho do romance, em especial, que é bastante ilustrativo dessa relação de aproximações e distanciamentos:

Fabiano ia satisfeito. Sim senhor, arrumara-se. Chegara naquele estado, com a família morrendo de fome, comendo raízes. Caíra no fim do pátio, debaixo de um juazeiro, depois tomara conta da casa deserta. Ele, a mulher e os filhos tinham-se habituado à camarinha escura, pareciam ratos - e a lembrança dos sofrimentos passados esmorecera.

Pisou com firmeza no chão gretado, puxou a faca de ponta, esgaravatou as unhas sujas. Tirou do aió um pedaço de fumo, picou-o, fez um cigarro com palha de milho, acendeu-o ao binga, pôs-se a fumar regalado.

- Fabiano, você é um homem, exclamou em voz alta.

Conteve-se, notou que os meninos estavam perto, com certeza iam admirarse ouvindo-o falar só. E, pensando bem, ele não era um homem: era apenas um cabra ocupado em guardar coisas dos outros. Olhou em torno, com receio de que, fora os meninos, alguém tivesse percebido a frase imprudente. Corrigiu-a, murmurando:

-Você é um bicho, Fabiano.

Isso para ele era motivo de orgulho.

- Sim senhor, um bicho capaz de vencer dificuldades (RAMOS, 2018, p. 4445). 
Sendo de comum acordo entre os comentadores da obra graciliânica, costuma-se dizer que Vidas secas é um romance onde o humano se animaliza (vezes muitas Sinha Vitória, Fabiano e seus dois meninos se comunicam grunhindo) e o bicho (no caso, a cachorra Baleia, que, morrendo, sonha com um céu cheio de preás) se humaniza. Parafraseando Nietzsche (2000), "um bicho, demasiado humano". Segundo Serafim (2005, p. 39), “A ternura, tênue, passa vagamente pela extensão do romance, permeando o vigor do embrutecimento, redefinindo a nulidade”. Mais uma vez citando Candido (1961, p. 39),

Parece que, fatigado da brutalidade esterilizante de Paulo Honório e do niilismo corruptor de Luís da Silva, quis oferecer da vida uma visão, sombria, é verdade, mas não obstante limpa e humana. Fabiano é um esmagado, pelos homens e pela natureza; mas o seu íntimo de primitivo é puro.

A fim de superar essa dicotomização clássica acerca da relação entre humanos e animais em Vidas secas, a ecocrítica feminista Donna Haraway nos oferece a noção de espécies companheiras, que promove a ruptura com o pensamento de que haja sujeitos e objetos pré-constituídos ou fontes únicas, agentes únicos ou fins últimos. "Um bestiário de agências, tipos de relações e contagens temporais superam as imaginações até mesmo dos cosmologistas mais barrocos. Para mim, isto é o que significa espécie companheira" (HARAWAY, 2017, p. 722). Isso nos leva para a abundante diversidade ecológica sem a qual a espécie humana não pode sobreviver. "Desta leitura que [Haraway] faz do mundo, perdem o sentido ('implodem') os binarismos que sustentam as tantas formas de opressão e destruição que são alvo de suas análises críticas” (CAVALCANTI e HARAN, 2017, p. 747). Nessa perspectiva, não há uma hierarquização nas relações entre Baleia e sua família de humanos: eles vivem juntos, numa relação de afeto e interdependência. O que chamamos de natureza humana seria uma relação interespécies.

Assim, podemos afirmar, sempre pensando numa unidade estética da obra romanesca de Graciliano Ramos, que Baleia e sua família de retirantes acabam praticando uma espécie de "antropofagia" ao devorarem o papagaio, logo no primeiro capítulo do romance. Esse ato antropofágico remete aos índios do romance histórico inacabado de João Valério, homem frustrado por ser um civilizado tentando entender o que é ser selvagem, assim como Paulo Honório que, desejoso de ser um sertanejo bronco nas mãos de um patrão, não consegue se livrar da vida ligada à escrituração mercantil, e Luís da Silva, que devaneava nos passeios pela praia, tentando escapar da vidinha de sururu que levava na capital. A família de retirantes de Vidas secas é o sonho irrealizado dos protagonistas dos três primeiros romances 
graciliânicos. Uma família composta por espécies companheiras. Uma família interespécies. Uma família caeté.

\section{CONSIDERAÇÕES FINAIS}

A ecocrítica apresenta uma distinção em relação às demais perspectivas literárias pois, para ela, o mundo não se reduz ao mundo social, mas envolve toda a ecosfera, incluindo a relação entre seres humanos e todas as outras formas de vida e de existência. $\mathrm{O}$ estudo da trajetória graciliânica, assimilando a noção bourdieusiana de espaço com a foucaultiana de heterotopia, pode nos conduzir na abordagem não só dos lugares percorridos nessa trajetória, isto é, os lugares da memória na obra, como também da própria obra como lugar outro da memória.

A mediocridade de João Valério, que se confunde na mediocridade citadino-provincial dos anos 1920; o distanciamento da vida ligada ao campo, ainda que exerça sobre ele um papel de domínio e exploração, é o distanciamento entre Paulo Honório e a humanidade: um distanciamento desumanizante e desumanizador, que reifica as pessoas e as reduz à sua propriedade; a angústia de Luís da Silva, que reflete a opressão sofrida/causada pela cidade grande, afundada na lama; a secura e a aridez da caatinga, que emudece a família de retirantes e permeia as suas vidas, são algumas marcas/sinais desse amalgamamento entre personagens e os cenários onde se desenrola o drama de suas existências.

Desse modo, pode-se concluir que a literatura de Graciliano é também, dentre tantos atributos, ecocrítica e ecosófica, no sentido de que promove a abertura às reflexões sobre os lugares onde foram produzidas e onde se passam as narrativas, abordando o cosmo social sem perder de vista a sua inserção no cosmo físico-natural.

\section{REFERÊNCIAS BIBLIOGRÁFICAS}

ALAIMO, Stacy. Trans-corporeal Feminisms and the Ethical Space of Nature. In: ALAIMO, Stacy; HECKMAN, Susan (Eds.). Material Feminisms. Bloomington: Indiana University Press, 2008. p. 237-263.

ALVES, Élder Patrick Maia. A economia simbólica da cultura popular sertanejonordestina. Maceió: EDUFAL, 2011.

BOURDIEU, Pierre. As regras da arte: gênese e estrutura do campo literário. São Paulo: Companhia das Letras, 1996. 
. Razões práticas: sobre a teoria da ação. Campinas: Papirus, 2003.

BRANDÃO, Izabel. A propósito de "feminismos transcorpóreos e o espaço ético da natureza", de Stacy Alaimo. Estudos Feministas, Florianópolis, 25(2): 562, maio-ago. 2017. Disponível em: <http://www.scielo.br/pdf/ref/v25n2/1806-9584-ref-25-02-00961.pdf >. Acesso em: 8 mar. 2020.

CANDIDO, Antonio. Ficção e confissão. In: RAMOS, Graciliano. Caetés. 6. ed. São Paulo: Livraria Martins Editora, 1961.

CAVALCANTI, Ildney; HARAN, Joan. O feminismo multiespécies de Donna Haraway. In: In: BRANDÃO, Izabel; CAVALCANTI, Ildney; COSTA, Claudia de Lima; LIMA, Ana Cecília Acioli. Traduções da Cultura: perspectivas críticas feministas (1970-2010). Florianópolis: EDUFAL, Editora da UFSC, 2017.

DELEUZE, Gilles; GUATTARI, Félix. Mil platôs: capitalismo e esquizofrenia 2, vol. 3. 2. ed. São Paulo: Editora 34, 2012.

ELIAS, Norbert. Mozart: a sociologia de um gênio. Rio de Janeiro: Zahar, 1995.

FERREIRA, Cosme Rogério. Habitus, campo e mercado editorial: a construção do prestígio da obra de Graciliano Ramos. Maceió: EDUFAL, 2015.

FOUCAULT, Michel. Outros espaços. In: Estética: literatura e pintura, música e cinema. Trad.: Inês Autran Dourado. 2. ed. Rio de Janeiro: Forense Universitária, 2009. p. 411-422.

GAARD, Greta. New Directions for Ecofeminism: Toward a More Feminist Ecocriticism. ISLE Interdisciplinary Studies in Literature and Environment, p. 1-23, 2010.

GLOTFELTY, Cheryll. Introduction-literary studies in an age of environmental crisis. In: GLOTFELTY, Cheryll; FROMM, Harold (eds.). The ecocristicism reader - landmarks in literary ecology. Athens / London. The Univ. of Georgia Press, 1996. p. 15-37.

GUIMARÃES, J. Ubireval Alencar. Graciliano Ramos e a fala das memórias. Maceió: EDICULTE/SECULTE, 1987.

HARAWAY, Donna. O Manifesto das espécies companheiras - cães, pessoas e alteridade significante [fragmento]. In: BRANDÃO, Izabel; CAVALCANTI, Ildney; COSTA, Claudia de Lima; LIMA, Ana Cecília Acioli. Traduções da Cultura: perspectivas críticas feministas (1970-2010). Florianópolis: EDUFAL, Editora da UFSC, 2017.

MICELI, Sergio. Vanguardas em retrocesso: ensaios de história social e intelectual do modernismo latino-americano. São Paulo: Companhia das Letras, 2012.

NIETZSCHE, Friedrich. Humano, demasiado humano. Trad.: Paulo Cezar de Souza. São Paulo: Companhia das Letras, 2000.

RAMOS, Clara. Mestre Graciliano: confirmação humana de uma obra. Rio de Janeiro: Civilização Brasileira, 1979. 
RAMOS, Graciliano. Caetés. 34. ed. Rio de Janeiro: Record, 2019.

Cartas. 8.ed. Rio de Janeiro: Record, 2011.

. São Bernardo. 86. ed. Rio de Janeiro: Record, 2008.

. Angústia. 71. ed. Rio de Janeiro: Record, 2019.

. Vidas secas. Rio de Janeiro: Record, 2018.

SERAFIM, Marcos Henrique Lucena. Os Heróis da Contra-Nulidade: um estudo do caráter afirmativo em Vidas secas, romance de Graciliano Ramos. 2005. 104f. Tese (Doutorado em Literatura) - Programa de Pós-Graduação em Letras e Linguística, Universidade Federal de Alagoas, Maceió.

Recebido: $20 / 03 / 2020$

Aprovado: 10/08/2020 